\title{
Ultimate load design of tall steel building frames allowing for instability
}

\author{
by \\ M. Holmes, B.Sc., Ph.D., A.M.I.C.E. \\ and \\ S. N. Gandhi, B.E., Ph.D., A.M.A.S.C.E.
}

Professor M. R. Horne and Dr K. I. Majid (University of Manchester) wrote that the ultimate load method proposed by the Authors was an interesting extension of methods previously suggested for the design of tall orthogonal frames. Directness of design was achieved by assuming simplified collapse mechanisms, here supplemented by amplification factors to allow for frame instability effects. This simplification appeared to have been achieved, however, at the expense of a considerable loss in economy, since it could not be ensured either that the distribution of hinges reflected the actual distribution or that it would result in an economic distribution of material. While some simplification was necessary for a satisfactory design procedure, the overestimate of weight appeared likely to be excessive in many cases. In obtaining the reduced plastic moment at collapse or in assessing the effect of instability, the axial loads in the members were assumed to be 0.875 times the working load on a span for the external columns and 1.75 times the adjacent span loads for an internal column. This greatly exaggerated the effect of instability and plasticity for those stories in Zones II and III, for which lateral loading (to a load factor of 1.4) was initial.

52. In certain instances the method could produce satisfactory results, for example, when dealing with frames of a few stories with large vertical loading and a relatively small wind load. The sheltered industrial building frame first analysed by Wood ${ }^{1}$ was a case in point. The good results in such frames were due to the fact that collapse took place with what approximated to a beam-type mechanism (Fig. 1(a) of the Paper) and instability effects were insignificant.

53. Unfortunately, the comparison made by the Authors between their design and Wood's frame was not as complete as it might have been. Whereas in Wood's frame the sections used were rolled steel joists with a yield stress of 15.25 ton $/ \mathrm{sq}$. in., the Authors adopted universal beams and columns with a yield stress of 16 ton/sq. in. Moreover, Wood's frame had a collapse load factor of about 1.90, whereas the Authors had designed a load factor of $2 \cdot 15$.

54. The contributors had therefore redesigned Wood's frame by the Authors' method, but using rolled steel joists and a load factor of 1.90. This gave designed full plastic moments as in Table 5, showing that the Authors' method gave results similar to Wood's frame for both beams and columns.

55. A complete assessment of any design method was impossible unless, for purposes of comparison, a collapse analysis was available, based on an accurate

- Proc. Instn civ. Engrs, vol. 30, January 1965, pp. 147-166.

${ }^{3}$ The references are listed on p. 340. 




(a) Frame and loading (tons)

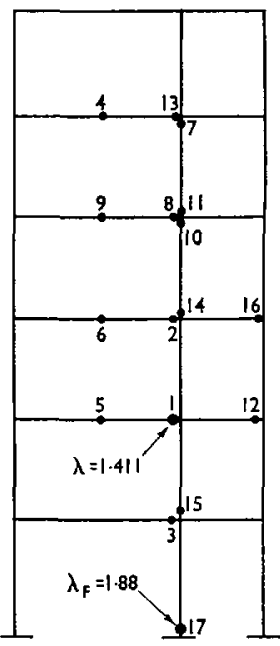

(b) Order of hinge formation using sections given in column 3, Table 2

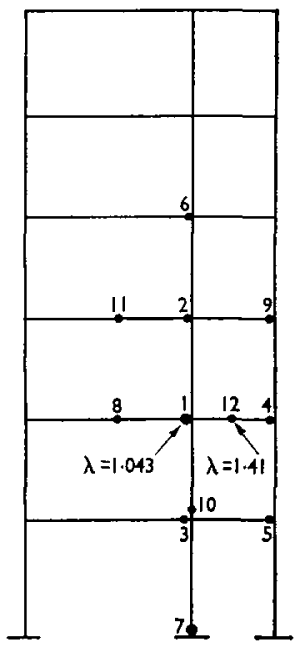

(c) Order of hinge formation using sections given in column 4, Table 2

FIG. 16: ANALYSIS OF SIX-STOREY, TWO-BAY FRAME

elastic-plastic method, allowing for stability. Such a programme had been devised for the Atlas computer ${ }^{\theta, 9}$ and had been used to analyse the six-storey, two-bay frame shown in Fig. 16(a). The working load (idealized as point loads in the figure) and storey heights were those used by the Authors in their fourth example, while the spans were $20 \mathrm{ft}$ and $10 \mathrm{ft}$ respectively.

56. The Authors had not given details as to how such unequal bays were to be dealt with, and so the contributors had used the method adopted in the Authors' - fourth example, viz. to assume two equal bays each of the larger span. While this led to an overestimate of the axial loads, the unsymmetrical nature of the vertical loading, aggravating sidesway, was ignored. Hence the general order of safety and

TABle 5: Modification of TABle 1 OF THE PaPer using Equations (14) to (22) FOR WOOD'S FRAME

\begin{tabular}{c|c|c}
\hline \multirow{2}{*}{ Storey } & \multicolumn{2}{|c}{ Selected sections Ton/in. } \\
\cline { 2 - 3 } & $M_{\mathrm{p}}$ of beams & $M_{\mathrm{p}}$ of columns \\
\hline 1 & $428(244)$ & $318(205)^{*}$ \\
\hline 2 & $428(428)$ & $318(259)$ \\
\hline 3 & $428(428)$ & $393(393)$ \\
\hline 4 & $428(428)$ & $502(502)$ \\
\hline
\end{tabular}

- Wood's figures in parentheses. 
TABLE 6: A COMPARISON OF TWO DESIGNS OF THE SIX-STOREY/TWO-BAY FRAME OF FIG. 16

\begin{tabular}{|c|c|c|c|c|}
\hline \multirow[t]{2}{*}{$\begin{array}{l}\text { Member } \\
\text { No. }\end{array}$} & \multicolumn{2}{|c|}{$\begin{array}{l}\text { Using the method of Holmes } \\
\text { and Gandhi }\end{array}$} & \multicolumn{2}{|c|}{$\begin{array}{l}\text { Using the elastic-plastic com- } \\
\text { puter analysis }\end{array}$} \\
\hline & $\begin{array}{c}\text { Assumed axial } \\
\text { load in design } \\
\text { (tons) }\end{array}$ & $\begin{array}{c}\text { Selected } \\
Z_{\mathrm{p}}(c u . \text { in. })\end{array}$ & $\begin{array}{c}\text { Selected } \\
Z_{\mathrm{p}}(c u . \text { in. })\end{array}$ & $\begin{array}{l}\text { Calculated axial } \\
\text { load at } \lambda_{2}=1 \cdot 4\end{array}$ \\
\hline 1 & 108 & 49 & $34 \cdot 7$ & $73 \cdot 8$ \\
\hline 2 & 0 & $61 \cdot 5$ & 44 & 0.04 \\
\hline 3 & 216 & $90 \cdot 6$ & 75 & 124 \\
\hline 4 & 0 & $61 \cdot 5$ & $29 \cdot 3$ & 0.07 \\
\hline 5 & 108 & 49 & $34 \cdot 7$ & $62 \cdot 1$ \\
\hline 6 & 88.4 & $39 \cdot 8$ & $30 \cdot 4$ & $61 \cdot 8$ \\
\hline 7 & 0 & 44 & 38 & 1.27 \\
\hline 8 & 177 & 75 & $60 \cdot 3$ & $104 \cdot 2$ \\
\hline 9 & 0 & 44 & $24 \cdot 1$ & 1.04 \\
\hline 10 & $88 \cdot 4$ & 39.8 & 30.4 & $46 \cdot 5$ \\
\hline 11 & $68 \cdot 9$ & $34 \cdot 7$ & $18 \cdot 9$ & $48 \cdot 5$ \\
\hline 12 & 0 & 44 & 38 & $2 \cdot 02$ \\
\hline 13 & 138 & $60 \cdot 3$ & $60 \cdot 3$ & $83 \cdot 5$ \\
\hline 14 & 0 & 44 & $19 \cdot 1$ & 0.027 \\
\hline 15 & $68 \cdot 7$ & $34 \cdot 7$ & $18 \cdot 9$ & $33 \cdot 3$ \\
\hline 16 & $49 \cdot 2$ & $30 \cdot 4$ & $15 \cdot 1$ & $35 \cdot 2$ \\
\hline 17 & 0 & 44 & 38 & $1 \cdot 70$ \\
\hline 18 & 98.4 & $39 \cdot 8$ & 39.8 & $61 \cdot 9$ \\
\hline 19 & 0 & 44 & $15 \cdot 8$ & 0.32 \\
\hline 20 & $49 \cdot 2$ & $30 \cdot 4$ & $15 \cdot 1$ & $21 \cdot 0$ \\
\hline 21 & $29 \cdot 5$ & $30 \cdot 4$ & $15 \cdot 1$ & $21 \cdot 7$ \\
\hline 22 & 0 & 44 & 38 & $1 \cdot 38$ \\
\hline 23 & 59 & $18 \cdot 9$ & $18 \cdot 9$ & $38 \cdot 0$ \\
\hline 24 & 0 & 44 & $15 \cdot 8$ & 0.75 \\
\hline 25 & $29 \cdot 5$ & $30 \cdot 4$ & $15 \cdot 1$ & $11 \cdot 3$ \\
\hline
\end{tabular}


TABLE 6-continued

\begin{tabular}{|c|c|c|c|c|c|}
\hline \multirow[t]{2}{*}{$\begin{array}{l}\text { Member } \\
\text { No. }\end{array}$} & \multicolumn{3}{|c|}{$\begin{array}{l}\text { Using the method of Holmes } \\
\qquad \& \text { Gandhi }\end{array}$} & \multicolumn{2}{|c|}{$\begin{array}{l}\text { Using the elastic-plastic com- } \\
\text { puter analysis }\end{array}$} \\
\hline & \multicolumn{2}{|c|}{$\begin{array}{l}\text { Assumed axial } \\
\text { load in design } \\
\text { (tons) }\end{array}$} & $\begin{array}{c}\text { Selected } \\
Z_{\mathrm{p}}(c u . \text { in. })\end{array}$ & $\begin{array}{c}\text { Selected } \\
Z_{\mathrm{p}}(\text { cu. in. })\end{array}$ & $\begin{array}{l}\text { Calculated axial } \\
\text { load at } \lambda_{2}=1.4\end{array}$ \\
\hline 26 & \multicolumn{2}{|c|}{$9 \cdot 83$} & $30 \cdot 4$ & $15 \cdot 1$ & $7 \cdot 3$ \\
\hline 27 & \multicolumn{2}{|c|}{0} & 38 & 38 & $2 \cdot 4$ \\
\hline 28 & \multicolumn{2}{|c|}{$14 \cdot 85$} & $18 \cdot 9$ & 18.9 & $12 \cdot 8$ \\
\hline 29 & \multicolumn{2}{|c|}{0} & 38 & $15 \cdot 8$ & 0.535 \\
\hline 30 & \multicolumn{2}{|c|}{$9 \cdot 83$} & $30 \cdot 4$ & $15 \cdot 1$ & $3 \cdot 54$ \\
\hline \multicolumn{4}{|l|}{ Total wt. } & \multicolumn{2}{|c|}{4.98 tons } \\
\hline \multicolumn{2}{|c|}{$\begin{array}{l}\text { horizontal deflexion } \\
\text { at } \lambda_{2}=1\end{array}$} & \multicolumn{2}{|c|}{$2.61 \mathrm{in}$. at top } & \multicolumn{2}{|c|}{$3.504 \mathrm{in}$} \\
\hline
\end{tabular}

economy were likely to reflect not unreasonably the results to be expected from the Authors' method. The frame was designed, using equations (14) to (22), to collapse at load factors of $\lambda_{1}(1 \cdot 75)$ and $\lambda_{2}(1.4)$ of the idealized loads. Details of the design were given in the second and third columns of Table 6 below.

57. On checking the collapse load of the frame so designed under vertical and horizontal loads, it was found that, at a load factor of $\lambda_{2}=1.4$ (the design load factor) the frame was still perfectly elastic. The first hinge was formed at $\lambda_{2}=1.411$ and final collapse took place at $\lambda_{2}=1 \cdot 88$.

58. The bending moments and axial loads in the members calculated by the computer at $\lambda_{3}=1.4$ were utilized to select the sections given in the fourth column of Table 6. The total weight of the frame was $31 \%$ less than that of the frame designed according to the Authors' method. An analysis of the revised frame gave a load factor at failure of $\lambda_{F}=1.41$.

59. It was apparent that, while the Authors had introduced some most useful ideas in the derivation of design methods for multi-storey frames, their method appeared to be insufficiently refined to achieve the economies to be expected from the use of ultimate elastic-plastic theory in design. It was to be hoped however that they would pursue their studies further to see whether refinements and modifications might be introduced to render the method more sensitive to actual collapse conditions.

The Authors, in reply, thanked Professor Horne and Dr Majid for contributing to the discussion of their Paper.

61. It was not necessary in the proposed method to use a load factor of 1.75 for reduced plastic moment and the effect of instability in the columns in Zones II and III, the factor 1.40 would be sufficient. Possibly some confusion arose on this point due to the adjustments made to Wood's loading in Examples 1 and 2 which were necessary to compare the results of analysis with those of design.

62. Unfortunately Horne and Majid chose a two-bay frame in which the spans were $10 \mathrm{ft}$ and $20 \mathrm{ft}$, i.e. a $100 \%$ difference between the two spans. The method mentioned in $\S 32$ for dealing with unequal spans, was suggested to be reasonable provided the difference in spans did not exceed $20 \%$. Hence the comparisons made in Table 6 did not necessarily reflect that the proposed method was in general con- 
servative, but rather that some modification was necessary when adjacent spans differed greatly. Such modifications were the subject of research being undertaken at the present time. In this example the adoption of a load factor of 1.75 for axial loads, irrespective of zone, would also tend to produce a conservative design.

63. Professor Horne and Dr Majid confined their comments to the ultimate load of the various structures designed in the Paper, but some reference should be made to permissible horizontal deflexion. The proposed design method limited the value of $A$ to a maximum of 2.0 (see $\$ 20$ ), to prevent designs being formulated which would have excessive deflexion. This limitation on A (which was not essential to the method, and could easily be removed) could, for example, result in a design which had a load factor against collapse which was greater than $\lambda_{2}=1.40$ in order to prevent excessive deflexion. A difficulty arose, however, in specifying a permissible deflexion, as the calculated deflexion (based on the bare frame) would always exceed that occurring in the actual structure due to the effects of cladding. The comparisons made in Table 6 showed that the lighter design resulted in a reduction in load factor of $25 \%$ at the cost of a $34 \%$ increase in horizontal deflexion at the working load.

64. Several six-storey, single-bay frames, designed by the methods given in the Paper, had recently been tested. At final collapse the average experimental value of $\lambda_{2}$ was $\mathbf{1 \cdot 8 5}$. There were several reasons for the experimental value of $\lambda_{2}$ exceeding $1 \cdot 40$, amongst them were the effects of strain hardening and the availability of sections (a section should always be chosen which had properties equal to or greater than those required).

\section{REFERENCES}

8. MAJid K. I. Ph.D. Thesis, Manchester University, 1963.

9. JENNINGS A. and MAJID K. I. Elastic-plastic analysis by computer for framed structures loaded up to collapse. J. Instn Struct. Engrs, 1965, 43, 12 (Dec.), 407-412. 